A major reason for failure to attend outpatient appointments is the inappropriateness of this offer. The appointment of ten involves a two-week delay and no offer to see the same interviewer, or the opportunity to contact him in the intervening time if necessary (the time of highest risk for repetition). I systematically visited overdose patients one week after the act and so often the story was that they had desperately needed to talk since discharge. They could not really see the point of going back to the clinic a week or more hence. Many still had a high level of neurotic symptoms.

There is no doubt that present psychiatric management of overdose patients is poor and ineffective and the need for change is urgent

J G B Newson-SMITH

I.ong Grove Hospital

E:psom, Surrey

\section{One drug for epilepsy}

SIR,-I was interested to note that Dr S D Shorvon and his colleagues (25 February, p 474) did not consider it necessary to use a concurrent control group in order to assess the additional benefit resulting from the use of drug blood level monitoring in the treatmen of epilepsy. I will therefore continue to wonder if a policy of gradual dose incremen for continuing seizures is really markedly improved by the addition of blood leve monitoring.

In addition, I am puzzled by the data presented in table II of their paper, especially when it is compared with the earlier report on the group treated with phenytoin.' Five patients fewer are now tabulated, but comparison of the present data with the earlier figures reveals that there are now one fewer patients controlled with suboptimum levels, four fewer controlled with optimum levels, and two fewer uncontrolled with levels always suboptimum. However, there are now two more cases classed as having been uncontrolled with suboptimum levels but controlled with optimum levels. Although a mean duration of follow-up is quoted, such figures are meaningless unless they apply to a specific time after commencement of treatment. To illustrate this point, the survival rates following cancer treatment are of value only if the time to which they refer is known.

K D MACRAE

Department of Medical Statistics,

Charing Cross Hospital Medical School,

London W6

Reynolds, E H, Chadwick, D, and (jalbraith, A W Lancet, 1976, 1, 923.

${ }_{*}^{*}$ We sent a copy of this letter to Dr Shorvon and his colleagues, whose reply is printed below.-ED, BMF.

SIR,-Dr MacRae has misunderstood the object of our trials (25 February, p 474). The value of drug blood level monitoring was not primarily in question. Ample evidence of its value has accumulated in many countries in the last 18 years. ${ }^{\cdots ;}$, The question we asked was: What is the value, if any, of polypharmacy - that is, adding a second or more drugs in patients uncontrolled by one? For these patients we planned to add either a second anticonvulsant or a placebo. However, as only $12 \%$ of our patients have failed so far on monotherapy, we are still unable to answer this question. As we discussed, our data suggest that the success of monotherapy was largely, but not wholly, due to the availability of drug level monitoring. There was a $98 \%$ reduction in grand mal attack rate in the optimum range for both phenytoin and carbamazepine. Without monitoring 60-70\% of our patients might possibly now be on multiple drugs instead of $12 \%$.

The difference between table 2 in our earlier report $t^{t}$ and the present report of the phenytoin trial are, as pointed out, due to changes in the outcome of therapy between the two times of follow-up (mean 14.7 months and 28.5 months), including the loss of four patients to follow-up and the withdrawal of one patient with a tumour. We are preparing a detailed report of the phenytoin trial, including case histories, which will describe the outcome in each individual patient.

Finally, we agree with Dr MacRae about the importance of duration of follow-up, a point we have always stressed. Indeed, among the numerous deficiencies of anticonvulsant trials a remarkable feature has been their brevity compared with the duration for which we usually treat our patients. ' This is all the more important as there is evidence that seizure control tends to deteriorate with increasing duration of follow-up." However, we do no understand Dr MacRae's reference to cancer statistics, as the problems of treating cancer and epilepsy are very different. While attempt are made to "cure" cancer, anticonvulsant drugs probably only "suppress" seizure during the time of their administration. It is not possible to relate our drug data to "a specific time after the commencement of treatment," as drug levels will often vary independently of duration of follow-up. In future, we believe prognostic studies in epilepsy will have to take more account of drug level monitoring.

SIMON SHORVON D CHADWICK

A W Galbraith E H REYNOLDS

University Department of Neurology,

Institute of Psychiatry,

London SE5

Buchthal, F, Svensmark, O, and Schiller, P J, Archives

of Neurology, 1960, 2, 624.
Kutt, $\mathrm{H}$, and Penry, J K, Archives of Neurology, 1974 31, 283.

I.und, I, Archives of Neurology, 1974, 31, 289.

Revnolds, F H, Proceedings of the Royal Society of Medicine, 1975, 68, 102.

ichens, A, Drug Treatment of Epilepsy. London, Henry Kimpton, 1976

Reynolds, E H, Chadwick, D, and Galbraith, A W Lancet. 1976, 1, 923

Coatsworth, J J, Ninds Monograph, No 12, 1971. Springfield, Illinois, C C Thomas, 1968.

\section{Happy to starve}

SIR,-Your leading article "Happy to starve" (8 April, p 874) draws attention to the possibility of underfeeding in some breast-fed babies and stresses the importance of regular weighing of babies. Paediatrics, as I believe Dr John Apley first said, is "a growing specialty" and any doctor seeing a child in his clinic or surgery is incompletely equipped if he does not have on his desk an appropriate percentile chart. For babies the most useful chart is the one drawn up by Gairdner and Pearson' and available from Creaseys Ltd of Hertford. Regular use of such charts is the only way to ensure that deviant growth, in either direction, is detected early. Hopefully the error involved in your misprint (the weekly weight gain should be around 190 or
$200 \mathrm{~g}$ and not $19 \mathrm{~g}$ ) is too gross to cause confusion.

Dudley Road Hospital,

D P ADDY Birmingham

' Gairdner, D, and Pearson, J, Archives of Disease in Childhood, 1971, 46, 783 .

\section{Safety in laboratories}

SIR,-Your leading article (8 April, p 871) suggests that some of the recommendations of the Howie working party are unrealistic.

What is even more unrealistic is your suggestion that laboratories might be inspected for safety by environmental health officers. These excellent and already overworked men and women have no training in laboratory procedures and rarely have any knowledge of microbiological hazards. Perhaps you mean Health and Safety Executive (factory) inspectors. Some of these are already well qualified to do this work, and I understand that others are in training.

Hadlow,
Kent

C H Collins

SIR,-With reference to your leading article on safety in laboratories (8 April, p 871), it is sometimes useful to express the alternative point of view. This joint hospital and public health laboratory functioned for more than a quarter of a century in an antiquated converted Victorian workhouse, much of the time without benefit of a single exhaust cabinet or other protective device, examining more than a million clinical specimens in microbiology, haematology, histopathology, and clinical chemistry. There was no evidence of ill health among our work force which could sensibly be attributed to conditions of work.

We now have up-to-date premises with numerous safety measures-though still not everything which the mind can devise. Though doubtless it could be said that in the past we did not look carefully enough for evidence of illness in our staff, I personally feel no greater sense of security as a result of modernisationon the contrary only more anxiety.

There was a time when, like the wellmotivated nurse, we put our service to the patient first in our thoughts. Can it be that something is now being lost? Certainly we are spending a great deal of money in the "safety" industry. I must add that we did not and still do not deal with work from kidney units or organ transplant patients. I think our staff are more at hazard coming to work than at work.

Microbiology Department,

D R Christie

Meratory Services,

County Hospital, Hereford

\section{Treatment of paracetamol poisoning}

SIR,-We have been interested to read the recent article (11 February, p 331) and correspondence (1 April, p 856) concerning the safety and efficacy of cysteamine and $\mathrm{N}$-acetylcysteine in the treatment of paracetamol poisoning. Since 1974 the National Poisons Information Service has advocated the use of oral methionine for the treatment of this condition, provided it is administered within 10 hours of ingestion of the overdose. ${ }^{1}$ Many hospitals have used methionine on our 
recommendation and we think it appropriate to give details of those cases of severe paracetamol poisoning treated with methionine that have been reported to us.

In a three-year period we have accumulated information on 116 patients who had high plasma paracetamol concentrations (falling above a line joining $200 \mathrm{mg} / 1$ at four hours and $80 \mathrm{mg} / \mathrm{l}$ at 12 hours post ingestion when plotted on a semilogarithmic paracetamol concentration-time scale) and who were treated with methionine. Seventyfour patients were given methionine within 10 hours of ingestion of the overdose and had serial liver function tests performed. Thirty-eight of 74 patients showed no abnormality of liver function and nine patients only had plasma aspartate aminotransferase (AAT) concentrations in excess of $250 \mathrm{IU} / 1$; three of these patients had maximum AAT concentrations in excess of $1000 \mathrm{IU} / 1$. All 74 patients made a satisfactory recovery with the exception of a 30-year-old woman who also ingested Dalmane, Indocid, and Tandalgesic besides paracetamol, and who died 53 hours after admission following a grand mal fit; the maximum plasma AAT concentration recorded was $53 \mathrm{IU} / 1$. A further 28 patients with high paracetamol levels received methionine within 10 hours of ingestion but did not have liver function tests performed; all 28 patients made a satisfactory recovery. In contrast, 14 patients with high paracetamol levels received methionine more than 10 hours after ingestion; 10 of these 14 patients recovered, but four patients subsequently died from liver failure.

Although cysteamine is effective in the treatment of paracetamol poisoning, ${ }^{2}$ the adverse effects make a less toxic alternative desirable. ${ }^{2-4}$ The early results obtained by Prescott et al (1 April, p 856) for intravenous $N$-acetylcysteine are promising, but we believe that there is sufficient evidence to continue recommending oral methionine as the treatment of choice for severe paracetamol poisoning.

T J MEREDITH P CROME GLYN VOLANS RoY Goulding

Poisons Unit, New Cross Hospital, London SE14

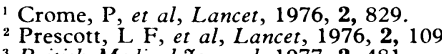

${ }_{3}^{3}$ British Medical fournal, 1977, 2, 48

Hughes, R D, et al, British Medical fournal, 1977, 2,
1395.

\section{What kind of cot death?}

SIR,-Your leader "What kind of cot death ?" (18 March, p 671) brought the welcome news that, for reasons yet obscure, the frequency of cot death in Britain may be declining. It is likely that the increasing frequency of breastfeeding accounts for this trend. ${ }^{1-}$

Sudden infant death syndrome (SIDS), the term applied in the United States to cot death in the baby who clinically and pathologically appears to have been well, also appears to be declining ${ }^{4}$ and, correspondingly, breast-feeding in the United States has been on the increase. For some years Sweden has had strikingly fewer cot deaths and substantially more breast-feeding than Britain or the United States. ${ }^{6}$ Furthermore, babies from lower socioeconomic classes everywhere are more likely to suffer cot deaths and less likely to be breast-fed. ${ }^{16}$

Discussion of the role of infant feeding in cot death or SIDS has been discouraged in some quarters in spite of the evidence. Confusion has occurred because, until recently, too few babies were exclusively breast-fed through the period of greatest risk to permit adequate comparisons. One question to be answered is, "How many deaths have occurred prior to six months in infants breast-fed with no cow milk formula supplements ?" One hopes that the DHSS multicentre study of postneonatal mortality has asked this question and that the mother-infant feeding histories will be sufficiently detailed to provide an answer.

Of the epidemiological factors implicated, the infant feeding method is the one mos amenable to change in any programme aimed at preventing cot death. Even if ongoing research into neural and cardiorespiratory mechanisms reveals the chain of events preceding unexpected death, we must still ask, "What is to be done ?" Differences between breastand bottle-feeding have important implications for the infectious, ${ }^{89}$ immunological ${ }^{11}$, metabolic, ${ }^{11} 12$ neural, and anatomical ${ }^{1: 3-15}$ correlates proposed for cot death. We could therefore expect reductions in all three cot death categories if babies are breast-fed longer and more exclusively.

Cot death can be seen as the large tip of the infant morbidity-mortality iceberg. It is important that we know, in very practical terms, what accounts for its decline.

Allan S Cunningham The Mary Imogene Bassett Hospital,

Cooperstown, New York

Sloper, K S, Elsden, E, and Baum, J D, Archives of Disease in Childhood, $1977, \mathbf{5 2}, 700$

Jepson, M E, et al, Lancet, 1976, 2, 425.

Peterson, D R, and Chinn, N M, Pediatrics, 1977, 60, 75

Filer, L J, jun, Hospital Practice, 1978, 13, 87

Vahlquist, B, Environmental Child Health, 1975, 21, 11 Cunningham, A S, and Beckwith, J B, Pediatrics, 1976 58,467 .

Downham, M A P S, et al, British Medical fournal $1976,2,274$

Cunningham, A S, fournal of Pediatrics, 1977, 90, 726 British Medical fournal, 1976, 2, 1167.

"Davies, D P, British Medical fournal, 1973, 2, 340.

Räihä, N C R, et al, $P$,

Lancet, 1977, 2, 1064 .

Tonkin, S, Pediatrics, $1975, \mathbf{5 5}, 650$.

Fetal malformation not associated with Debendox

SIR,-The report by Drs Dian Donnai and R Harris (18 March, p 691, and subsequent letters 8 April, p 925), drawing attention to an apparent association between the use of Debendox and an unusual malformation syndrome, is very interesting and could obviously be an important early warning of a new drug-induced abnormality. However, as is conceded in the article, Debendox has been widely used in early pregnancy with apparent safety for a long time, and with any such extensively used drug there will be the coincidental association of its use with malformation syndromes. We would like to report a further identical case, in which Debendox was not implicated.

A 32-year-old primagravida was delivered at term of a male baby who lived for an hour. Multiple congenital abnormalities were obvious, including complete exomphalos, absent right leg and right half of pelvis, absent right kidney, left hydronephrosis, abnormal lumbar spine, and small right hemithorax. No drugs were prescribed or taken in the first trimester apart from iron. There was possible contact with rubella in the first month, and at 13 weeks a flu-like illness was treated with ampicillin, codeine linctus, and paracetamol. Investigation of the baby showed a normal karyotype (including Giemsa banding) and no viruses were isolated. The mother had a rubella antibody (haemagglutination inhibition) titre of
1/16. No conclusive aetiological association was therefore established.

As a number of cases of this very unusual and apparently rare malformation syndrome, without any clear genetic or environmenta aetiology, have been reported in a short time, we would suggest that this mini-epidemic be looked at more closely and that any other cases be reported until aetiological associations (Debendox or other) become established.

Alan KoHN

Department of Paediatrics,

Alan Parsons

Good Hope Hospital,

Sutton Coldfield

SIR,-Drs Dian Donnai and R Harris (18 March, p 691) reported three cases in which an unusual congenital abnormality followed treatment with Debendox (dicyclomine hydrochloride $10 \mathrm{mg}$, doxylamine succinate $10 \mathrm{mg}$ pyridoxine hydrochloride $10 \mathrm{mg}$ ) in early pregnancy. We would like to report a case of similar abnormality (exomphalos, reduction deformity of one leg, and thoracic kyphoscoliosis) in a patient who took no antiemetic but in whom ovulation was induced with Clomid (clomiphene citrate).

The patient, a 21-year-old primigravida, was first seen in the gynaecological clinic in January 1977 complaining of secondary amenorrhoea and infertility. After investigation she was treated with clomiphene citrate, $50 \mathrm{mg}$ daily for five days, and became pregnant after the first cycle of treatment She took no drugs during the first trimester. She was admitted in November 1977 at 32 weeks gestation because of premature rupture of the membranes. Two days later she delivered a male infant weighing $1470 \mathrm{~g}$ with multiple abnormalities, who died after 40 minutes.

Post-mortem examination showed exomphalos containing most of the abdominal contents. The right hip and upper part of the femur were absent so that the right lower limb was attached to the pelvis by skin and soft tissue only. There was a severe thoracic kyphoscoliosis and in addition hydrocephalus, anorectal atresia and an absent left kidney.

The abnormalities found in this baby are strikingly similar to those described by Drs Donnai and Harris, and their occurrence in the absence of treatment with an antiemetic perhaps suggests either that the association with Debendox was fortuitous or that this combination of abnormalities is commoner than generally recognised.

We thank Professor H G Dixon for his permission to report this case.

DAVID H A REDFORD IAN LEWIS

Department of Obstetrics and Gynaecology, University of Bristol

\section{Effect of maternal diazepam on the} newborn

SIR,-May I commend Dr R J Rowlatt's warning (15 April, p 985) on the hazards of diazepam in labour, which echo my own fears ?' In addition to those he mentions is the effect on the fetal heart, which loses its beat-to-beat variation. It is suggested ${ }^{2}$ that this reflects a loss of adaptive ability of the fetal heart and circulatory system, or is possibly due to a depression of the cardiac reflex centres in the brain. Moreover, the common metabolic pathway that diazepam shares with bilirubin (being conjugated with glucuronic acid) means that its detoxification could result in raised bilirubin levels and even kernicterus in the 